\title{
An Analysis of the Innovation Path of the Crisis Management Mechanism of the University Campus in China
}

\author{
Keyan Wang \\ School of Materials and Chemical Engineering, Hainan University, Haikou Hainan, 570228, China
}

Keywords: Colleges and universities, Campus crisis management, Mechanism innovation, path.

\begin{abstract}
Currently, China is in the period of social transformation, massive internal and external of college and universities environment changes create frequent crisis in campus. Although some progress have gained some improvement in crisis management of colleges and universities in China recently, there are still some more problems. In order to improve the level of China's university campus crisis management, this article put forward the innovation of management mechanism to deal with campus crises to solve these problems,based on the description of the campus crisis, further analyzes the existing campus crisis management mechanism China.
\end{abstract}

\section{Introduction}

With continues increasing enrollment of higher education, the scale, level and forms in collages and university made great changes, the traditional stable campus management mode is stable with relatively closed environment is no longer applicable to the current situation. When facing series of new problems in college campus, especially the frequent campus crisis events, the traditional university management mechanism and management mode often do not know what to do, solve all kind of campus crisis effectively in the shortest possible, or take any measure from ,or take feasible the measures for prevention of various types of campus crisis. The university campus supposed to be the place to train the future builders of the country, which is directly related to the harmony and stability of the society. Our university administrators must have a clear understanding of their missions and responsibilities. Based on the actual situation of our universities, combined with the current internal and external environment of universities in China, we propose targeted solutions to campus crisis events in China. Therefore, we should find out the innovation path of campus crisis management mechanism, minimize the adverse impact of campus crisis on students and society, and become a main content in current university management activities.

\section{Scope of campus crisis}

Campus crisis refers to the sudden or imminent occurrence of adverse effects on university teachers and students, campus stability and social stability. During the period of social transformation, universities are facing more and more complex internal and external environment. Which leads to the diversification and complexity of campus crisis in China. Different from the general social crisis, the college campus crisis has both the characteristics of the social crisis and its unique characteristics. On the basis of the case of campus crisis in recent years, we can see that the crisis events in college campus have the following characteristics:

First of all, the campus crisis is sudden events, often without warning, and due to many complicated factors, the managers are not expected to the events of time and place, to take corresponding measures to prevent the occurrence of campus crisis; Secondly, campus crisis is dangerous. The occurrence of campus crisis will pose serious threats to school's normal order, property and even life, resulting in adverse consequences on campus and society. Thirdly, campus crisis events in Colleges and universities are diffused. The openness of university campus makes the relationship between universities and society more and more close. Universities are an important base for training talents, deeply concerned by the government and the public. Once a crisis occurs, it is 
easy to become the focus of social attention. The network information technology coupled with the now highly developed, once the campus crisis events, the network will be in a very short time of information release, spread to every corner of the world, making the situation further; fourth, campus crisis of group. College students are the main body, they are in physical and mental development of the individual and psychological immature contradictions period, in the face of life choices often rebellious, confused, must continue to break the psychological balance has to find a new balance, which leads to confusion of college students often in mood and behavior, both thinking agility again, the lack of rational, it is easy to make extreme behavior, and easy to incite by others. If the university administrators can not persuade them in time, it is likely to cause serious consequences; fifth, the campus crisis events are linked. As a subsystem of the society, the students' students' status is not only related to the students' individual, but also to thousands of families. Once students encounter the campus crisis, their connectivity directly affects the arteries of the whole society.

\section{Problems in the crisis management mechanism of the traditional university campus}

\subsection{Lacking sound prevention mechanism for college campus crisis}

\subsubsection{Lack of an effective university campus crisis management institution}

Nowadays, most of the crisis management institutions in our university campus are composed of the principals, the principals and the secretaries of various disciplines. Members not only shoulder the task of teaching and management, work safety will be responsible for the crisis, in a multitasker case, once the campus crisis events, crisis management mechanism is difficult to deal with the crisis event in the first time, and it is prone to buck responsibility, good communication and coordination to deal with the crisis

\subsubsection{Lack of college campus crisis education mechanism}

Nowadays, many colleges and universities are still unaware of the importance of crisis management and lack of vigilance on campus crisis events. Many colleges and universities pay attention to the campus crisis management only, and have not established the corresponding crisis education mechanism. Therefore, colleges and universities must include crisis prevention mechanism in daily education management, and use lectures, forums and other forms to make college teachers and students have a clearer understanding of campus crisis.

\subsubsection{Lack of sound early warning system for college campus crisis}

Some university campus crisis events will have certain symptoms before they break out. If colleges and universities can establish a sound campus crisis warning system, we can track and catch signs of crisis and minimize reaction time. However, at present, there is no sound early warning system for campus crisis in Colleges and universities. After the outbreak of campus crisis, colleges and universities often fall into a passive way, and need to be treated temporarily

\subsection{Lack of perfect college campus crisis coping mechanism}

\subsubsection{Lack of coordination among departments}

Currently, most colleges and universities is still departmental fragmentation management. Once the campus crisis happens, the way of reporting gradually is difficult to form effective regulation. The division of rights and responsibilities between departments is not clear, subordinates are accustomed to obey the above institutions, the administrative examination and approval is complicated, and so on, which seriously reduces the coordination ability among departments, and makes the management work of colleges and universities inefficient, and the campus crisis response mechanism is missing. At the same time, due to lack of information communication channels, after the occurrence of campus crisis, colleges and universities can not communicate with educational administration departments in a timely manner, which seriously affects the effectiveness of crisis management in universities. 


\subsubsection{Lack of perfect legal guarantee}

At present, our country has not set up a real sense of the campus crisis management law. Schools often face an awkward situation when dealing with campus crisis events. The court in the treatment of campus crisis, often according to the "Regulations on administrative penalties for public security", "Education Law", "higher education law" and other relevant laws and policies of discretion, but these laws mainly focused on crime, tort, violation of public security and so on, exorbitant discretionary power may affect the rights and interests of victimization.

\subsection{Lack of effective evaluation mechanism for college campus crisis recovery}

The lack of psychological intervention in the crisis management center is the main reason for the failure of the evaluation mechanism of the campus crisis recovery. After the outbreak of the campus crisis, colleges and universities will not only cause physical and physical injury to teachers and students, but also form certain psychological trauma. In contrast, psychological and mental injuries are the hardest to recover. Specifically, the lack of psychological intervention in the crisis management center is mainly shown in the following aspects

\subsubsection{Formalization of mental health education}

Universities often focus on achievements rather than the influence of psychological factors on students' behaviors, so that they neglect the mental health education of students. At the same time, most colleges and universities have the situation of insufficient investment in mental health education funds, which cannot provide material guarantee for mental health education.

\subsubsection{Lack of professional psychological counseling teachers}

In addition to professional psychology part is provided with a university in the professional psychological counseling teachers, most of universities have not established the professional psychological counseling teachers, some psychological counseling teachers are part-time management personnel, there are some psychological counseling teachers are teaching staff positions concurrently, these teachers play multiple roles and the lack of professional, once the outbreak of campus crisis. It is difficult for students to conduct effective psychological intervention.

\subsubsection{Lack of correct understanding of psychological consultation}

As a new subject, psychological counseling has a unique sense of mystery, and many teachers and students in many colleges and universities have some more or less prejudice. A part of teachers and students believe that people who conduct psychological counseling may suffer from mental illness, or even have problems in moral quality. There are still a part of teachers and students who are afraid that their secrets are being leaked and do not want to communicate with psychological counselling teachers.

\section{Innovation path of college campus crisis management mechanism in China}

\subsection{Establishing and perfecting the prevention mechanism of college campus crisis}

\subsubsection{Establishing a good university campus crisis management institution}

The members of the crisis management institution on the campus should be composed of all the personnel related to the crisis, the administrator of the University, the counselor, the lawyer and so on. By college administrators and discipline responsible person in charge of the work of campus crisis management decision-making; by counselors, teachers and administrators responsible for campus crisis management implementation; by counselors, lawyers, teachers, social workers and other related responsible for campus crisis management assistance work.

\subsubsection{Establishing a good college campus crisis education mechanism}

To improve students' sense of crisis is an important prerequisite for improving campus crisis 
coping ability, university administrators must be integrated into the crisis consciousness in the teaching process, the teachers and students can take time for in the face of campus crisis. Educators in Colleges and universities should give full play to their educational functions, adopt classroom education, lectures, forums, campus media and other ways, so that teachers and students can clearly understand the time of crisis and further enhance the awareness of teachers and students.

\subsubsection{Establishing and perfecting the early warning system of college campus crisis}

The establishment of campus crisis early warning system can collect timely signs of crisis events, and stifle crises in time to minimize the occurrence of campus crisis. The crisis management plan is the main part of the crisis management work in Colleges and universities, mainly by university crisis management, overall plan and special emergency plans and temporary emergency plan, with the initiative, flexibility and operability characteristics, improve the crisis early warning system for Campus.

\subsection{Establishing a perfect college campus crisis coping mechanism}

\subsubsection{Enhancing the coordination capacity of various departments}

After the occurrence of campus crisis, university crisis management leading group should have a comprehensive understanding of the situation, analyze the causes, process and results of the crisis, and report it to the education department in a timely manner. When dealing with campus crisis management, colleges and universities should coordinate all resources that can be utilized, maximize the role of the existing materials, rationally and effectively deploy the existing manpower, material and financial resources, and effectively ensure the progress of crisis management. Meanwhile, colleges and universities should establish effective information communication channels, communicate with teachers, parents and news media after the crisis time, and minimize the adverse effects caused by campus crisis

\subsubsection{Strengthening the construction of the legal system of crisis management in Colleges and Universities}

The United States established campus police in early 60s of last century, and then established the "campus safety law". Developed countries such as Sweden, Australia and other developed countries have also formulated the corresponding "campus safety law" according to their national conditions. China should actively learn from the experience of advanced countries, integrate resources, speed up the pace of legislation for campus safety, and establish a more perfect campus safety legal system, so that university campus crisis management can be legally regulated.

\subsection{Establishing an effective evaluation mechanism for college campus crisis recovery}

\subsubsection{After treatment}

University campus crisis can cause casualties. University administrators must timely appease the victims and their families, and comprehensively assess the losses caused by the crisis, and give the victims the appropriate pension. Campus crisis can cause students material and physical damage, but also will cause some psychological trauma to the teachers and students in the campus, the outbreak of crisis, universities should actively adopt psychological intervention, psychological intervention from the school, family and society three aspects, to minimize the adverse effects caused by campus crisis.

\subsubsection{Restoration and reconstruction}

After the crisis of college campus is controlled, the restoration of normal teaching and the daily management become the main task of the crisis management. In the stage of restoration and reconstruction, colleges and universities should gradually abolish the emergency management measures and restore normal teaching and management of colleges and universities. For the school buildings, teaching tools and network communications that are destroyed in the campus crisis, the responsible person should make a comprehensive statistics of the damage and rebuild and repair 
according to the actual situation of our school. 3. Image reconstruction

The outbreak of the campus crisis can easily damage the image of the school. For the damage caused by campus crisis, colleges and universities should take the initiative to take the responsibility, apologize to the public and teachers and students, and timely announce the remedial measures of the school, calm down the closure of campus crisis, and minimize the extent of the damage of the school image. At the same time, colleges and universities should carry out propaganda and communication in a variety of ways to let the public see the sincerity of the students and realize the "crisis" to the "chance".

\section{Conclusion}

In a word, the campus crisis after the outbreak of the incident, the staff of crisis management in Colleges and universities should cause, process and results of a comprehensive investigation of the incident, in-depth analysis of colleges and universities in the management and operation of procedural deficiencies, and make timely modifications and adjustments, for the follow-up of the crisis management work experience. The innovation of campus crisis management mechanism helps to improve the level of campus crisis management in China, and plays a crucial role in maintaining campus and social stability.

\section{Acknowledgement}

This research was financially supported by the special subject of Marx theory and ideological and political education in Hainan higher schools, number: Hnsz2016-16.

\section{References}

[1] Zhang Rensong, Chen Zhaoxin. Chinese employment, college students working ability of counselors to respond to emergencies, 2012, 10.

[2] Shu Yan, Wan Changye, Tang philosopher. The approach to the prevention and control of crisis management in college campus, financial economy, 2017, (20).

[3] Wang Zi Han. Based on the theory of crisis management, the research on the construction of safe campus in Colleges and universities, talent resources development, 2016, (18).

[4] Hou Yanli, the high mountains of No university crisis management gap organization theory of enterprises in Hebei, 2015, (02).

[5] Liu Xingwang, Zhang Shanwei. Multiple cooperative governance -- the new direction of the university campus crisis management, 2016, (07). 